\title{
Effect of hydrostatic pressure on microbial degradation and bacterial community composition of model diatom aggregates
}

PETER STIEF, CLEMENS SCHAUBERGER, JOHN PAUL BALMONTE AND RONNIE N GLUD

University of Southern Denmark

Presenting Author: peterstief@biology.sdu.dk

Phytoplankton aggregates forming in the sunlit layers of the ocean are densely colonized by bacteria and other microbes that exploit the entrapped organic matter while the aggregates sink to the deep ocean. Diatom-dominated aggregates are particularly fast-sinking due to the ballasting effect of the silica shells. Hence, microbes attached to diatom aggregates are quickly exposed to high levels of hydrostatic pressure, which significantly slows down microbial activity and thus aggregate degradation. We hypothesize that the partial inhibition of overall microbial activity is explained by the suppression of piezosensitive bacteria attached to the aggregates.

Using 16S rDNA amplicon sequencing, we show that the pressure-induced decrease in microbial activity was accompanied by substantial changes in bacterial community composition during 1-day incubations in a rotating pressure tank. Bacterial groups apparently not adapted to the fast increase in pressure level were eliminated from the community, while a core bacterial community remained present up to the highest pressure levels tested (i.e., $100 \mathrm{MPa}$ corresponding to $10 \mathrm{~km}$ water depth). Pressure exposure promoted also the leakage of dissolved organic carbon (DOC) from the diatom cells. It can be speculated that the ample supply of DOC inside the aggregates was exploited by piezo-tolerant or piezo-philic bacteria that endured the high pressure levels.

In conclusion, (1) the partial inhibition of aggregate degradation by pressure will enhance the amount of labile organic matter that is deposited on the seabed, while (2) the suppression or promotion of different bacterial groups by pressure will re-shape the microbial communities that make it from surface waters to the deep sea. 